\title{
KONTRIBUSI ANTARA KEKUATAN OTOT TUNGKAI DAN KEKUATAN OTOT PUNGGUNG TERHADAP KEMAMPUAN BANTINGAN PINGGANG OLAHRAGA GULAT ATLET PGSI PROVINSI BENGKULU
}

\author{
Martiani \\ Universitas Dehasen Bengkulu \\ Email: annie.phaph@unived.ac.id
}

\begin{abstract}
This study was conducted to determine the contribution of leg muscle strength and back muscle strength to the ability of the waist beating scientifically. The formulation of the problem in this research is how much contribution of leg muscle strength and back muscle strength together to the ability of waist beating in wrestling? This research was conducted in wrestling sasana PGSI of Bengkulu Province. The research method used is correlation method with product moment and double correlation, the samples are research 30 wrestling atlets of PGSI Bengkulu Province taken with total sampling technique. The result of data Rcount $=0.91>R_{\text {table }}=0.361$ then Ho is rejected and Ha is accepted, it means that there is a meaningful relationship between $X_{1}$ and $X_{2}$ together with $Y$. Contribution of arm muscle strength and back muscle strength to the ability of waist beating that is $K=r 2 \times 100 \%=$ $82.81 \%$. So it can be concluded that there is a positive contribution between leg muscle strength and back muscle strength to the ability of waist beating by $82.81 \%$.
\end{abstract}

Keywords: leg muscle strength, back muscle strength, waist beating ability.

\begin{abstract}
ABSTRAK
Penelitian ini dilakukan untuk mengetahui kontribusi kekuatan otot tungkai dan kekuatan otot punggung terhadap kemampuan bantingan pinggang secara ilmiah. Adapun rumusan masalah dalam penelitian ini adalah berapa besar kontribusi kekuatan otot tungkai dan kekuatan otot punggung secara bersama-sama terhadap kemampuan bantingan pinggang dalam olahraga gulat? Penelitian ini dilakukan di sasana gulat PGSI Provinsi Bengkulu. Metode penelitian yang digunakan adalah metode korelasi product moment dan korelasi ganda, sampel penelitian berjumlah 30 atlet gulat PGSI Provinsi Bengkulu yang diambil dengan teknik total sampling. Adapun hasil data $\mathrm{R}_{\text {hitung }}=0,91>\mathrm{R}_{\text {tabel }}=0,361$ maka Ho ditolak dan $\mathrm{Ha}$ diterima artinya terdapat hubungan yang berarti antara $X_{1}$ dan $X_{2}$ secara bersama-sama dengan $\mathrm{Y}$. Kontribusi kekuatan otot lengan dan kekuatan otot punggung terhadap kemampuan bantingan pinggang yaitu $K=r^{2} x 100 \%=82,81 \%$. Sehingga dapat disimpulkan bahwa adanya kontribusi positif antara kekuatan otot tungkai dan kekuatan otot punggung terhadap kemampuan bantingan pinggang sebesar $82,81 \%$.
\end{abstract}

Kata Kunci: kekuatan otot tungkai, kekuatan otot punggung, kemampuan bantingan pinggang. 


\section{PENDAHULUAN}

Dalam perkembangannya, olahraga telah menjadi kebutuhan bagi masyarakat untuk meningkatkan dan menjaga kondisi tubuh agar tetap sehat dan bersemangat dalam melakukan kegiatan sehari-hari serta dapat diandalkan untuk mengharumkan nama bangsa melalui prestasi. Demi tercapainya prestasi yang baik dan maksimal perlu dilaksanakan pembinaan olahraga yang dilakukan dengan mengadakan perkumpulan olahraga. Kemudian diadakan kompetisi secara berjenjang dan berkelanjutan untuk dijadikan sebagai tolak ukur sukses atau tidaknya pembinaan olahraga yang dilakukan. Pembinaan dan pengembangan olahraga sudah menjadi tanggung jawab bersama dimulai dari pusat hingga ke daerah-daerah melalui induk organisasi yang ada guna pencapaiaan prestasi yang maksimal, diantaranya prestasi olahraga Gulat yang ada di Provinsi Bengkulu. Salah satu pembinaan prestasi olahraga Gulat yang ada di
Provinsi Bengkulu yaitu melalui pengurus daerah PGSI Provinsi Bengkulu.

Prestasi olahraga tidak sematamata ditentukan oleh kemahiran menguasai teknik saja, akan tetapi juga ditentukan oleh persiapan melalui latihan maksimal secara sistematis dan berkelanjutan. Begitu juga pada olahraga gulat, Suharno dalam Nuh (2012: 2) menyatakan: "Ada 4 (empat) elemen dasar yang mendukung, yaitu (1) Kondisi fisik, yang bertujuan agar kemampuan fisik atlet meningkat pada kondisi puncak yang berguna untuk melakukan aktifitas olahraga dalam pencapaian prestasi. (2) Mental, merupakan daya penggerak dan pendorong untuk menjalankan kemampuan fisik, teknik dan taktik dalam melakukan aktivitas olahraga. (3) Teknik, merupakan suatu teknik gerakan dan pembuktian pada praktek dengan sebaik mungkin untuk penyelesaian yang pasti dalam cabang olahraga. (4) Taktik, merupakan siasat akal yang digunakan pada saat pertandingan untuk mencari kemenangan secara sportif." 
Olahraga gulat merupakan cabang olahraga bela diri yang menggunakan gerakan-gerakan kombinasi tarikan, dorongan, mengangkat dan putaran serta menitik beratkan pada teknik bantingan, gulungan dan kuncian yang dilakukan dalam usaha untuk mengurangi kesetabilan lawan dan meningkatkan gerakan serangan dalam satu set. Kurniawan (2012: 125), mengemukakan hal serupa "Gulat adalah olahraga kontak fisik antara dua orang, di mana salah seorang pegulat harus menjatuhkan atau dapat mengontrol musuh mereka." Gerakan-gerakan dasar tersebut sangat penting sehingga harus dilatih secara terus-menerus. Untuk itu tidak hanya latihan teknik yang diperlukan tetapi juga latihan berbagai komponen fisik sebagai pendukung penampilan saat bertanding.

"Olahraga gulat terdiri atas dua gaya yang dipertandingkan yaitu Gaya Bebas (Freestyle) dan gaya YunaniRomawi (Greco-Roman)" (Oktara, 2010: 172). Pada olahraga gulat Gaya Bebas
(Freestyle), seorang pegulat diperbolehkan untuk menggunakan kaki dalam menyerang lawanya atau bertahan, menangkap kaki lawan, mengait kaki lawan dan menggunakan kaki secara aktif untuk menyerang, dengan kata lain pegulat diperbolehkan menggunakan seluruh bagian anggota badan untuk melakukan serangan. Sedangkan di dalam gaya Yunani-Romawi (Greco-Roman) seorang pegulat dilarang keras untuk menyerang di bawah garis pinggang, mengait kaki lawan atau menggunakan kaki secara aktif untuk melakukan suatu gerakan.

Di dalam olahraga gulat gaya bebas terdapat berbagai teknik serangan atas, yaitu: tangkapan kaki, tangkapan satu kaki, tangkapan dua kaki, tarikan lengan, bantingan bahu, kayang depan, kayang samping, kayang belakang, sedangkan pada gaya Yunani-Romawi (Greco-Roman) terdapat berbagai teknik serangan atas, yaitu: bantingan pinggang, bantingan leher, bantingan lengan, bantingan sway, kayang 
depan, kayang samping, kayang belakang, Sudrajat dalam Adha (2013: 05).

Salah satu teknik dalam olahraga gulat yaitu teknik bantingan yang merupakan serangan yang memiliki nilai. Teknik bantingan dilakukan dengan mengangkat lawan yang kemudian dilanjutkan dengan gerakan menjatuhkanya ke matras. Teknik bantingan terdiri dari beberapa macam yaitu tenik bantingan pinggang, teknik bantingan bahu, teknik bantingan kayang, dll. Rubianto Hadi dalam Juhanis, (2012: 61). Teknik bantingan pinggang merupakan teknik gulat gaya YunaniRomawi (Greco-Roman) yang sering digunakan dalam setiap latihan maupun pertandingan, karena jika seorang pegulat berhasil melakukan teknik bantingan pinggang dalam latihan atau pertandingan maka seorang pegulat dengan mudah mengungguli lawannya. Untuk melakukan suatu teknik bantingan diperlukan beberapa komponen yang harus dilatih secara terusmenerus guna memperoleh hasil yang maksimal. Komponen-komponen yang di- butuhkan antara lain: kekuatan otot, genggaman jari-jari tangan dan kecermatan atlet.

Fox dalam Deshari (2010: 9) menyatakan bahwa "Kekuatan atau strength adalah suatu gaya sekelompok otot yang digunakan untuk melawan atau menahan beban dalam waktu maksimal." Kekuatan otot sangat penting dalam olahraga gulat, khususnya dalam teknik bantingan karena tanpa adanya kekuatan otot yang baik maka tidak akan tercipta suatu teknik bantingan yang baik, begitu juga sebaliknya dengan kekuatan otot yang baik maka akan tercipta suatu suatu teknik bantingan yang baik. Kekuatan otot tungkai dan kekuatan otot punggung dirasa memiliki peranan yang sangat dominan pada teknik bantingan gulat, hal ini dimaksudkan agar pelatih lebih memberikan bentuk latihan yang lebih spesifik guna keberhasilan teknik bantingan yang didukung oleh kondisi fisik atlet itu sendiri. 
Kekuatan otot yang digunakan dalam teknik bantingan, khususnya dalam teknik bantingan pinggang antara lain: kekuatan otot tungkai, kekuatan otot punggung dan kekuatan otot lengan. Kekuatan otot lengan berfungsi untuk menarik dan mendorong lawan guna menghilangkan kestabilan dalam bertahan, tentunya gerakan menarik dan mendorong ini sangat didukung oleh kekuatan otot tungkai seseorang dalam hal ini pada kuda-kuda kaki yang kemudian dilanjutkan dengan menopang berat badan lawan pada teknik gerakan mengangkat lawan.

Kekuatan otot punggung berfungsi untuk menopang badan lawan ketika akan diangkat dan akan dilakukan bantingan. Genggaman jari-jari tangan berfungsi untuk menjaga lawan agar tetap berada dalam penguasaan dengan cara mengaitkan kedua tangan ketika menguasai lawan. Genggaman tangan yang kurang kuat akan mengakibatkan pegulat kehilangan lawan (karena perlawanan) saat melakukan penyerangan. Sedangkan kecermatan adalah bagaimana cara seorang pegulat membaca peluang dengan cara melihat waktu yang tepat dalam menyerang. Penyerangan dilakukan saat lawan lengah terhadap posisinya sehingga penyerangan itu akan berhasil, penyerangan yang dilakukan di saat lawan dalam posisi siap kemungkinan besar akan mengalami kegagalan karena lawan akan segera mengeblok dan kembali menyerang.

Kekuatan merupakan salah satu komponen yang sangat penting untuk menunjang aktivitas fisik. Kerja otot yang maksimal dapat meningkatkan kemampuan kerja seseorang yang pada akhirnya akan meningkatkan prestasi individu dalam berolahraga. Senada dengan hal itu Irianto (2002:66) menyatakan "Kekuatan adalah kemampuan otot atau sekelompok otot untuk mengatasi tahanan. Kekuatan dikelompokan menjadi beberapa jenis, yaitu: (1) Kekuatan umum, (2) Kekuatan khusus, (3) Kekuatan eksplosive, (4) Kekuatan daya tahan, (5) Kekuatan maksimum, (6) Kekuatan absolut, dan (7) Kekuatan re- 
latif”. Kekuatan memegang peranan penting dalam melindungi otot dari kemungkinan cedera, dengan kekuatan atlet akan dapat lebih cepat melakukan teknik yang diinginkan dalam cabang olahraga.

Jati (2007: 79) menyatakan bahwa "Otot bekerja secara kontraksi (otot memendek) dan relaksasi (otot memanjang)", kontraksi dan relaksasi otot tidak dilakukan secara bersamaan. Setelah otot berkontraksi, otot akan kembali ke keadaan semula atau relaksasi. Senada dengan hal itu Lesmana (2013) menyatakan bahwa "Daya tahan otot adalah kemampuan otot untuk mengulangi kontraksi dalam jumlah tertentu." Jadi, kekuatan otot seiring berjalan dengan daya tahan otot untuk melakukan gerak yang terarah. Daya tahan otot sendiri dipengaruhi oleh sistem energi yang digunakan oleh otot tersebut.

Atmojo (2007: 54) menyatakan: Kelentukan punggung bagian bawah berkaitan dengan rentang gerak yang didapatkan pada perototan punggung bagian bawah. Otot-otot, tendo-tendo, dan ligamen-liga- men cenderung untuk mempertahankan atau meningkatkan elastisitasnya melalui aktivitas peregangan, mereka yang fleksibel jarang/kurang mendapatkan cedera selama melakukan kegiatan jasmani, biasanya memiliki postur yang sehat dan jarang mengalami sakit. Otot punggung perlu dilatih agar lebih kuat menyangga tubuh, dan tak mudah cedera. Dengan otot punggung yang kuat maka seluruh aktivitas sehari-hari akan menjadi lebih mudah, begitu juga dengan olahraga.

\section{METODE PENELITIAN}

\section{Jenis Penelitian}

Penelitian ini menggunakan uji korelasi (corelation research), yang bertujuan untuk melihat hubungan antara variabel bebas dan variabel terikat. Tempat penelitian ini dilakukan di Gedung Sasana Gulat Provinsi Bengkulu yang beralamatkan di Jl. Cendana Sawah Lebar tepatnya di samping Stadion Semarak Kota Bengkulu. Penelitian ini menggunakan metode total sampel (total sampling), di 
mana seluruh populasi dijadikan sebagai sampel yaitu seluruh atlet Gulat PGSI Provinsi Bengkulu sebanyak 30 orang.

Teknik pengumpulan data menurut Sugiyono (2013: 2), yaitu metode atau cara ilmiah yang digunakan untuk mendapatkan data dengan tujuan dan kegunaan tertentu. Instrumen untuk mengukur kekuatan otot tungkai dan kekuatan otot punggung pada penelitian ini digunakan item tes pengukuran, back and leg dynamometer (Arsil, 2010: 81-82). Dengan reabilitas untuk kekuatan otot tungkai yang dimodifikasi dilaporkan koefisien reabilitasnya 0,90 dan koefisien validitasnya adalah 0,86 sedangkan tes kekuatan otot punggung memiliki reabilitas 0,97 dan validitas 0,97 . Tes dilakukan dengan dua kali percobaan dan diambil nilai tertinggi.

Instrumen tes untuk mengukur kemampuan bantingan pinggang yaitu dengan cara membanting lawan secepat mungkin dengan teknik yang benar selama 30 detik, Juhanis (2012). Hal senada dikemukakan oleh Edy Santoso melalui wawancara bahwa "Tes bantingan pinggang dilakukan selama 30 detik dengan menggunakan media alat yaitu boneka." Penggunaan boneka bertujuan agar pada saat pelaksanaan tes lawan tersebut bertahan atau dengan kata lain agar tidak ada perlawanan dari lawan yang akan dibanting”.

Uji statistik dalam penelitian ini dilakukan dengan uji normalitas data dan uji homogenitas varians, kemudian dilakukan uji korelasi yaitu untuk mengetahui hubungan antara kekuatan otot tungkai $\left(\mathrm{X}_{1}\right)$ dan kekuatan otot punggung $\left(\mathrm{X}_{2}\right)$ terhadap kemampuan bantingan pinggang dalam olahraga gulat (Y). Setelah itu dilakukan uji korelasi berganda yaitu untuk mengetahui seberapa besar hubungan antara kekuatan otot tungkai dan kekuatan otot punggung secara bersama-sama terhadap kemampuan bantingan pinggang dalam olahraga gulat atlet gulat PGSI Provinsi Bengkulu ditentukan dengan rumus: $\mathrm{K}=\mathrm{r}^{2} \times 100 \%$. 
Tabel 1. Hasil Uji Normalitas

\begin{tabular}{|c|l|c|c|l|}
\hline No & Variabel & $\mathbf{X}_{\text {hitung }}$ & $\mathbf{X}_{\text {tabel }}$ & Keterangan \\
\hline 1 & Kekuatan Otot Tungkai $\left(\mathrm{X}_{1}\right)$ & 0,1285 & 0,161 & Normal \\
\hline 2 & Kekuatan Otot Punggung $\left(\mathrm{X}_{2}\right)$ & 0,1594 & 0,161 & Normal \\
\hline 3 & Kemampuan Bantingan Pinggang $(\mathrm{Y})$ & 0,1546 & 0,161 & Normal \\
\hline
\end{tabular}

Tabel 2. Data Standar Deviasi dan Varians

\begin{tabular}{|c|l|c|c|}
\hline No & \multicolumn{1}{|c|}{ Variabel } & $\begin{array}{c}\text { Standar } \\
\text { Deviasi (S) }\end{array}$ & $\begin{array}{c}\text { Varians } \\
\left(\mathbf{S}^{\mathbf{2}} \mathbf{)}\right.\end{array}$ \\
\hline 1 & Kekuatan Otot Tungkai $\left(\mathrm{X}_{1}\right)$ & 8,49 & 72,08 \\
\hline 2 & Kekuatan Otot Punggung $\left(\mathrm{X}_{2}\right)$ & 13,2 & 174,20 \\
\hline 3 & Kemampuan Bantingan Pinggang (Y) & 7,5 & 56,20 \\
\hline
\end{tabular}

\section{HASIL DAN PEMBAHASAN}

Hasil

Dari hasil pengukuran kekuatan otot tungkai yang dilakukan terhadap atlet Gulat PGSI Provinsi Bengkulu didapat skor tertinggi 140 dan skor terendah 109, berdasarkan data kelompok tersebut ratarata hitung (mean) 125 dan simpangan baku (standar deviasi) 8,49 . Hasil pengukuran kekuatan otot punggung yang dilakukan terhadap atlet Gulat PGSI Provinsi Bengkulu didapat skor tertinggi 161 dan skor terendah 96, berdasarkan data kelompok tersebut rata-rata hitung (mean) 126,8 dan simpangan baku (standar deviasi) 13,2. Hasil tes kemampuan bantingan pinggang yang dilakukan terhadap atlet Gulat PGSI Provinsi Bengkulu didapat skor tertinggi 39 dan skor terendah 12, berdasarkan data kelompok tersebut ratarata hitung (mean) 24,7 dan simpangan baku (standar deviasi) 7,5. Hasil uji normalitas data masing-masing variabel tersaji dalam tabel 1 .

Diketahui varians ketiga variabel dalam penelitian ini adalah kekuatan otot tungkai $\left(\mathrm{X}_{1}\right)$, kekuatan otot punggung $\left(\mathrm{X}_{2}\right)$, dan kemampuan bantingan pinggang (Y) yang tersaji pada tabel 2.

Rumus penghitungan:

$$
F_{\text {hitung }}=\frac{\text { Varians Terbesar }}{\text { Varians Terkecil }}
$$




$$
F_{\text {hitung }}=\frac{174,20}{56,20}=\mathbf{3 , 0 9}
$$

Dari perhitungan yang telah dilakukan, didapatkan nilai $F_{\text {hitung }}=3,09$ sedangkan nilai $\mathrm{F}_{\text {tabel }}$ pada taraf signifikan $\alpha=$ 0,05 dengan $\mathrm{dk}=(\mathrm{b}),(\mathrm{n}-1)=(1),(30-1)=$ 1, 29 di mana 1 sebagai pembilang dan 29 sebagai penyebut adalah sebesar 4,18. $F_{\text {hitung }}<F_{\text {tabel }}$ yaitu $3,09<4,18$ ini berarti tidak terdapat perbedaan dari masingmasing variabel atau harga variansnya homogen.

Berdasarkan analisis data didapat $\mathrm{r}_{\text {hitung }}=0,82$ dan $t_{\text {hitung }}=4,14$, berarti ada hubungan yang signifikan antara kekuatan otot tungkai terhadap kemampuan bantingan pinggang. Kontribusi kekuatan otot tungkai terhadap kemampuan bantingan pinggang yaitu $K=r^{2} \times 100 \%=(0,82)^{2} x$ $100 \%=67,24 \%$. Jadi, dapat disimpulkan kontribusi kekuatan otot tungkai dengan kemampuan bantingan pinggang adalah sebesar $67,24 \%$. Untuk mengetahui kualitas keberartian regresi antara variabel dilakukan uji “'t”. Dari perhitungan didapatkan nilai $t_{\text {hitung }}=4,14$ dengan $\mathrm{n}=30$ sedangkan $t_{\text {tabel }}$ pada taraf signifikan $\alpha=0,05$ diperoleh 2,048 yang lebih besar dari tabel sehingga dapat disimpulkan bahwa korelasi antara kekuatan otot tungkai dengan kemampuan bantingan pinggang adalah signifikan.

Berdasarkan analisis data didapat $\mathrm{r}_{\text {hitung }}=0,84$ dan $\mathrm{t}_{\text {hitung }}=14,8$, berarti terdapat hubungan yang signifikan antara kekuatan otot punggung terhadap kemampuan bantingan pinggang. Kontribusi kekuatan otot punggung terhadap kemampuan bantingan pinggang yaitu $K=(0,84)^{2}$ $\mathrm{x} 100 \%=70,56 \%$. Jadi, dapat disimpulkan kontribusi kekuatan otot punggung dengan kemampuan bantingan pinggang pada olahraga gulat adalah sebesar 70,56\%. Untuk mengetahui kualitas keberartian regresi antara variabel dilakukan uji " $t$ ". Dari perhitungan didapatkan nilai $t_{\text {hitung }}=$ 14,8 dengan $\mathrm{n}=30$ sedangkan $\mathrm{t}_{\text {tabel }}$ pada taraf signifikan $\alpha=0,05$ diperoleh 2,048 yang lebih besar dari tabel sehingga dapat disimpulkan bahwa korelasi antara kekuatan punggung dengan kemampuan ban- 
tingan pinggang dalam olahraga gulat adalah signifikan.

Berdasarkan perhitungan data ternyata $R_{\text {hitung }}=0,91>R_{\text {tabel }}=0,361$ maka Ho ditolak dan Ha diterima, artinya terdapat hubungan yang berarti $\mathrm{X}_{1}$ dan $\mathrm{X}_{2}$ secara bersama-sama terhadap Y. Kontribusi kekuatan otot tungkai dan kekuatan otot punggung terhadap kemampuan bantingan pinggang yaitu $\mathrm{K}=\mathrm{r}^{2} \times 100 \%=$ $(0,91)^{2} \times 100 \%=82,81 \%$. Jadi, dapat disimpulkan kontribusi kekuatan otot tungkai dan kekuatan otot punggung terhadap kemampuan bantingan pinggang adalah sebesar $82,81 \%$.

\section{Pembahasan}

Berdasarkan hasil analisis yang dikemukakan dan dari hasil pengujian hipotesis pertama ternyata diterima kebenarannya bahwa ada hubungan yang signifikan antara kekuatan otot tungkai dengan kemampuan bantingan pinggang dalam olahraga gulat. Semakin kuat otot tungkai, maka semakin baik pula kemampuan membantingnya. Kekuatan otot tungkai merupakan kekuatan otot lokal untuk menerima beban secara maksimal saat bekerja terutama sangat diperlukan oleh seorang pegulat. Kekuatan otot tungkai diperlukan untuk pertahanan diri hal ini pada kuda-kuda kaki yang kemudian sangat mendukung kekuatan otot lengan dalam upayanya menarik dan mendorong lawan guna menghilangkan kesetabilan dalam bertahan, tentunya gerakan menarik dan mendorong ini membutuhkan kemantapan berdiri dengan kuda-kuda kaki yang dilanjutkan dengan menopang berat badan lawan pada teknik gerakan mengangkat badan dalam upayanya melakukan bantingan yang baik.

Berdasarkan hasil analisis dan hasil pengujian hipotesis kedua ternyata diterima kebenarannya yaitu ada hubungan yang signifikan antara kekuatan otot punggung terhadap kemampuan bantingan pinggang dalam olahraga gulat. Semakin kuat otot punggung, maka semakin baik pula kemampuan bantingan pinggangnya. Dengan demikian seorang pegulat harus memiliki 
kekuatan otot punggung yang baik sehingga menghasilkan bantingan yang baik pula. Sesuai dengan kesimpulan dari materi (Juhanis, 2012: 63), menyatakan otot punggung berfungsi untuk menopang tubuh lawan setelah diangkat menggunakan pinggang untuk kemudian dihempaskan atau dibanting ke matras. Bantingan pinggang dapat dipengaruhi oleh beberapa unsur, di antaranya kecepatan, kekuatan dan ketepatan.

Hipotesis ketiga yang diajukan diterima kebenarannya yaitu ada hubungan yang signifikan antara kekuatan otot tungkai dan kekuatan otot Punggung terhadap kemampuan bantingan pinggang dan dapat disimpulkan bahwa semakin kuat otot lengan dan semakin kuat otot punggung maka semakin baik kemampuan bantingan pinggang yang dicapai. Sumber tenaga yang dipakai pegulat dalam melakukan teknik bantingan agar menghasilkan bantingan yang sempurna yaitu apabila menggunakan tarikan lengan yang dibantu oleh gerakan pinggang yang dikombinasikan serta didukung oleh kekuatan otot tungkai dan otot punggungnya. Gagalnya seorang pegulat dalam melakukan teknik bantingan pinggang disebabkan oleh beberapa faktor, antara lain: kurang baiknya teknik, konsentrasi, taktik dan kondisi fisiknya. Berkaitan dengan itu Harsono dalam (Retno, 2013: 5) menyatakan bahwa "Untuk meningkatkan keterampilan dan prestasi atlet yang maksimal, ada empat aspek latihan yang perlu diperhatikan dan dilatih secara seksama oleh atlet antara lain: latihan fisik, teknik, taktik, dan mental”.

\section{KESIMPULAN DAN SARAN}

\section{Kesimpulan}

Dari hasil penelitian, pengolahan dan analisa data, maka dapat ditarik kesimpulan yaitu berdasarkan hasil penelitian yang dilakukan di Sasana Gulat PGSI Provinsi Bengkulu dengan menggunakan uji normalitas data, uji homogenitas, uji hipotesis dan uji korelasi ganda, maka dapat dikemukakan kesimpulan bahwa ada kontribusi positif yang signifikan antara kekuatan otot tungkai dan kekuatan otot 
punggung terhadap kemampuan bantingan pinggang dalam olahraga gulat yaitu sebesar $82,81 \%$.

\section{Saran}

Setelah mengetahui hasil dari penelitian ini penulis mengemukakan beberapa saran, antara lain sebagai berikut:

1. Bagi Pelatih gulat agar dapat memberikan materi yang tepat kepada seorang pegulat khususnya untuk melatih kekuatan otot tungkai dan kekuatan otot punggung yang didukung dengan materi lainnya guna meningkatkan kemampuan bantingan pinggang sehingga dapat mendukung dalam penciptaan poin dengan mudah.

2. Bagi atlet agar dapat mengembangkan kemampuan gulat dalam melakukan teknik bantingan pinggang khususnya berdasarkan analisa yang telah diteliti dalam penelitiaan ini.

3. Bagi Dosen atau guru pendidikan jasmani dan olahraga kiranya dapat menganalisa variabel-variabel lain untuk meningkatkan kemampuan bantingan pinggang dalam olahraga gulat.

4. Bagi Peneliti yang ingin melanjutkan penelitian ini agar dapat menjadikan penelitian ini sebagai bahan informasi dan meneliti dengan populasi atau sampel yang berbeda dan dalam jumlah yang lebih banyak.

\section{DAFTAR PUSTAKA}

Adha, Ramadi. (2013). Pengaruh latihan kekuatan otot punggung dan tungkai terhadap bantingan kayang (laporan hasil penelitian). Jambi: FKIP Universitas Jambi.

Arsil. (2010). Evaluasi pendidikan jasmani dan olahraga. Malang: Wineka Media.

Atmojo, Mulyono Biyakto. (2007). Tes pengukuran pendidikan jasmani/ olahraga. Surakarta: Lembaga Pengembangan Pendidikan (LPP) UNS dan UPT Penerbitan dan Percetakan UNS (UNS Press).

Deshari. (2010). Kontribusi daya ledak otot tungkai terhadap tendangan sabit pada olahraga karate (laporan hasil penelitian). Padang: FPOK IKIP Padang.

Irianto, Djoko Pekik. (2002). Dasar kepelatihan. Yogyakarta: Surat Perjanjian Pelaksanaan Penulisan Diktat. 
Jati, Wijaya. (2007). Aktif biologi pelajaran biologi untuk SMA/MA. Jakarta: Ganeca Exact.

Kurniawan, Feri. (2012). Buku pintar pengetahuan olahraga. Jakarta: Laskar Aksara.

Nuh, Muhammad. (2013). Kontribusi kekuatan otot lengan terhadap kemampuan menggulung pinggang pada olahraga gulat (laporan hasil penelitian). Bengkulu: FKIP Universitas Bengkulu.

Oktara, Bebbi. (2010). Cabang olahraga populer aktivitas ketangkasan dan bela diri. Jakarta: CV. Bina Muda Cipta Kreasi

Sugiyono. (2012). Metode penelitian kuantitatif kualitatif dan $r \& d$. Bandung: PT Alfabeta.

\section{Sumber Lain: Internet.}

Juhanis. (2013). Hubungan kekuatan otot tungkai dan kekuatan otot lengan dengan kemampuan bantingan pinggang pada olahraga gulat mahasiswa fik unm makassar (laporan hasil penelitian). Makassar: FIK Universitas Negeri Makassar From http://digilib.unm.ac.id/files/disk1/ 8/universitas\%20negeri\%20makass ar-digilib-unmjuhanis-361-17.juhan-c.pdf

Lesmana, Syahmirza Indra. (2013). Kekuatan otot. From http://www.esaunggul.ac.id/article/ perbedaan-pengaruh-metodelatihan-beban-terhadap-kekuatandan-daya-tahan-otot-bicepsbrachialis-ditinjau-dari-perbedaangender-studi-komparasipemberian-latihan-beban-metodedelorme-dan-metode-oxford/. 24 Oktober 2017.

Retno. (2012). Gizi gulat PPA Semarang. http://retnotbs.files.wordpress.com/ 2013/10/gizi-gulat-ppasemarang1.pdf 